Ensino e Geografia

\title{
Construindo uma metalinguagem didática: o geozine na prática docente
}

\author{
Second constructing a didactical metalenguage: geozine in teaching \\ practice
}

\author{
João Paulo Teixeira Viana'(i), Eugênia Maria Dantas'
}

' UFRN, Departamento de Geografia, Natal, RN, Brasil

\section{RESUMO}

A pesquisa propõe um estudo sobre estratégias de ensino para os conteúdos geográficos escolares, tendo o Geozine como fonte para o seu desenvolvimento. O propósito central desta pesquisa é compreender o Geozine como uma linguagem transitiva que se comporta como uma estratégia didáticapedagógica para o ensino da Geografia escolar. Metodologicamente, realizou-se o aprofundamento do referencial teórico a partir da seleção de autores que abordam temas sobre a língua, linguagem e comunicação e sua interface com o ensino da geografia, os conceitos geográficos de Lugar e Paisagem e por fim, sobre o Fanzine e Geozine. A compreensão se dá a partir da exploração das noções de lugar e de paisagem, tendo, primeiramente, como foco uma oficina de construção didática denominada de "O Geozine: Construindo uma metalinguagem didática" destinada aos professores de Geografia da cidade de Taipu-RN. Todo este percurso serviu para dar uma maior densidade à linguagem Geozine e para enfatizar como ela pode ser aplicada, transitiva e metalinguística no fazer pedagógico do professor.

Palavras-chave: Geozine; Ensino de Geografia; Linguagem; Estratégia Didática

\section{ABSTRACT}

The research proposes a study on teaching strategies for school geographic contents, having Geozine as a source for its development. The central purpose of this research is to understand Geozine as a transitive language that behaves as a didactic-pedagogical strategy for the teaching of school Geography. Methodologically, it was carried out the deepening of the theoretical framework from the selection of authors who approach themes about language, language and communication and its interface with the teaching of geography, the geographical concepts of Place and Landscape and finally, about Fanzine and Geozine. The understanding is based on the exploration of the notions of place and landscape, having, first of all, as a focus a didactic construction workshop called "The Geozine: Building a didactic metalanguage" for the Geography teachers of the city of Taipu-RN. This whole course served to give 
more density to Geozine language and to emphasize how it can be applied, transitive and metalinguistic in the teacher's pedagogical doing.

Keywords: Geozine; Teaching Geography; Language; Didactic Strategy

\section{INTRODUÇÃO}

A educação representa uma atividade de intenso trabalho, tendo início no núcleo familiar e ampliando-se para a escola no que tange ao processo de formação social. O ensino é uma das maneiras de alcançar à aprendizagem, ou seja, o aluno não aprende se não obtiver um estímulo ou uma orientação acerca dos deveres da vida cotidiana. Sendo assim, as estratégias didáticas são um norteador importante na formação do aluno ao longo de sua jornada escolar.

Nessa conjuntura, o professor de Geografia, levado para esse cenário, é desafiado a criar estratégias de ensino que induzam o aluno a experimentar a Geografia Escolar como um campo aberto à inovação, o que supõe lidar com o universo informacional e com as diferentes linguagens que estão no cotidiano, aproximando a realidade vivida àquela a ser estudada. Dessa perspectiva, a Geografia Escolar passa por processos de reelaboração em que o perfil do professor se refaz para se aproximar das mudanças que o ensino e a aprendizagem têm requerido nessas primeiras décadas do século XXI.

O Geozine é uma metalinguagem, na medida em que se organiza no trânsito entre diferentes expressões, sem que haja redução entre elas. A força didáticopedagógica dessa metalinguagem, no âmbito do ensino de Geografia, está em favorecer a integração entre as diferentes maneiras de decodificação das ações dos homens e da natureza registradas na paisagem e no lugar.

A partir destes questionamentos, o propósito central desta pesquisa é compreender o Geozine como uma linguagem transitiva, desenvolvida como uma estratégia didático-pedagógica para o ensino da Geografia Escolar. Essa compreensão se dá a partir da exploração das noções de lugar e de paisagem, 
tendo como foco os professores de Geografia das instituições da rede pública da cidade de Taipu (Rio Grande do Norte).

Dessa forma, a elaboração do Geozine é voltada, primeiramente, para a formação dos professores de Geografia das três instituições de ensino de Taipu, pois ser docente é ser um ator social para a sociedade e para o espaço escolar. 0 professor, ao aprender sobre o recurso, pode aplicar e ampliar o seu fazer pedagógico, ressignificando continuamente a sua prática didática e metodológica.

Todavia, a escolha do professor e não do aluno parte do entendimento de que, para ensinar, é preciso que o professor experimente a estratégia antes de sua aplicação. Essa experimentação antecipada irá favorecer a avaliação, a crítica e a adequação no fazer pedagógico do docente. Ele é um sujeito capaz de pensar nas linguagens e estratégias didáticas que possibilitam a construção de um ensino e de uma aprendizagem significativa. Assim, o Geozine, como uma estratégia, possibilita aos educadores explorar, com os educandos, a confecção de um produto simples em sua construção, mas completo no que diz respeito à diversidade de linguagens que ele pode mobilizar (desenhos, músicas, charges, poesias, etc.).

Metodologicamente, a pesquisa é de cunho qualitativa exploratória onde busca através da linguagem Geozine, ser aplicada como uma estratégia pedagógica durante a realização de um oficina de construção didática com docentes da cidade de Taipu/RN. Também houve a realização de um estudo referencial e bibliográfico sobre língua, linguagem e comunicação e a linguagem Geozine.

Nesse contexto da realidade de vivências de professores e alunos, surge a proposta desta pesquisa, ao aproximar o cotidiano com as leituras das paisagens, dos cheiros, das percepções e do pertencimento do lugar, através de uma linguagem denominada Geozine, produto criado por Silva (2018) no Programa de Pós-Graduação Profissional em Geografia da UFRN, tendo como premissa a metalinguagem. Assim, o autor considera o Geozine como um objeto prático para o ensino da Geografia, que tem como princípios de construção o Fanzine ou Zine, 
porém ressignificando para a ciência geográfica escolar. Logo, compreende um leque de possibilidades, de experimentações e de expressões, na liberdade de quem o elabora e nos caminhos das ressignificações para o ensino de Geografia.

\section{GEOZINE: LÍNGUA, LINGUAGEM, COMUNICAÇÃO E ENSINO DE GEOGRAFIA}

A concepção do Geozine criada por Silva (2018) sugere a abertura para diversas possibilidades de apreensão. Por vezes, pode-se tê-lo como produto, por vezes apresentá-lo como metodologia, ainda concebê-lo como recurso. De uma perspectiva complexa, elas se interligam quando se pensa o Geozine como uma metalinguagem que opera a partir do "contrabando" de diferentes meios comunicativos para compor uma estratégia didático-pedagógica voltada para o ensino de Geografia.

Sabendo que o Geozine é uma linguagem que se transmuta sob diferentes aspectos didáticos, ora recurso, ora produto, ora estratégia, reflete-se, agora, sobre a noção da comunicação linguística no ensino de Geografia. Edgar Morin (2001) sugere três pontos fundamentais e primordiais para a reconstrução do conhecimento, sendo o pensamento e o ensino que servem como esclarecedores e que ajudam a entender o Geozine ora como linguagem, ora como método, ora como estratégia.

O primeiro ponto é considerar o problema do método. Este método não pode ser confundido com metodologia, visto que metodologia são caminhos e sequências traçados para o desenvolvimento de uma pesquisa. Já método é a formação da capacidade cognitiva do indivíduo em elaborar estratégias, fazendo contexto das informações, tornando o ser apto a tomar decisões e formar discussões.

A estratégia é descrita pelo autor como algo que "permite, a partir de uma decisão inicial, encarar um certo número de cenários para a ação, cenários que 
poderão ser modificados segundo as informações que vão chegar no decurso da ação e segundo os imprevistos que vão surgir e perturbar a ação" (MORIN, 2007, p. 116).

Em sequência, há a segunda premissa, que diz respeito à linguagem, sobre a qual Morin considera polivalente e polifuncional, pois exprime, constata, transmite, argumenta, dissimula, proclama e prescreve (os enunciados "performativos" e "ilocutórios"). Para Morin, tudo passa pela linguagem e, na maioria das vezes, faz dela um simples instrumento de transmissão ou um "caminho" para a realidade humana. As palavras, os sons e as imagens trabalham como uma trama que não se desvelam sem um dispositivo de análise próprio. Assim, a linguagem, na concepção de Edgar Morin, deve ser pensada em seu sentido hologramático, sendo parte integrante da cultura que a forma e concebida, ao mesmo tempo, como autônoma e dependente.

Por fim, em terceiro, parte da provocação de que a ampliação do conhecimento se dá pela migração entre áreas distintas do saber; em outras palavras, sob o olhar transdisciplinar dentro dos aspectos linguísticos polissêmico e polifônico das ciências. Mesmo sabendo que uma disciplina se propõe em construir determinados conhecimentos no âmbito da sua ciência, consegue estabelecer conexões e diálogos entre os diversos saberes.

Dessa forma, as acepções de Morin (2003) trazem fortalecimento teórico para o Geozine, mostrando que as mediações e intencionalidades comunicacionais são estratégias por transcender a perspectiva da fragmentação do conhecimento, favorecendo o trabalho docente como horizontes de possibilidades. Por fim, estabelece um diálogo multidisciplinar, algo característico na materialização do Geozine enquanto um produto didático.

A essas afirmações/premissas, acrescenta-se a noção de comunicação como o campo onde os sujeitos se situam para compreender o que está a sua volta e a si mesmo. Sobre isso, Paul Claval discute essa teia comunicacional, afirmando que "a esfera de contato é criadora dos círculos de intersubjetividade, na qual a 
mediação se realiza pela comunicação (textual, oral, midiática etc.)" (CLAVAL, 1995, p. 25).

A comunicação apresenta duas bases: uma analítica, baseada em estruturações de informação (espaço físico), e uma simbólica, orientada a aproximar ou, mesmo, distanciar por meio dos valores encadeados (espaço psicológico). Já em outra perspectiva, Claval (2002a) referência o papel das comunicações e das representações na passagem das mensagens que difundem conhecimentos e problemas de comunicação.

Percebe-se que há um elo entre os eixos cultura, comunicação, representação, códigos, signos e o desenvolvimento da Geografia dentro de uma abordagem cultural. Essa Geografia dialoga com aquela denominada de "Virada Linguística", baseada nas filosofias da linguagem de Ludwing Wittgenstein e Mikhail Bakthin, autores de grande importância na compreensão da linguagem e comunicação do Geozine.

$\mathrm{O}$ ato de comunicar envolve a operação com uma linguagem multiforme e heteróclita (SAUSSURE, 1989). A característica apontada pelo linguista tem contornos importantes para pensar o Geozine como um exercício de montagem a partir de materiais que podem vir de diferentes origens. O seu campo comunicacional se forma nesse contexto, pelo trânsito que os indivíduos são capazes de realizar para criar interpretações sobre o mundo, as coisas, os objetos, e o conhecimento.

Interfere, nesse processo de criação, os vínculos existenciais dos quais todos são partícipes. O pertencimento a uma língua, por exemplo, pode ser visto como um condicionante para as escolhas no processo de montagem. Para Bakhtin (1992), a língua seria formada por um conjunto de manifestações linguísticas, ou seja:

A verdadeira substância da língua não é constituída por um sistema abstrato de formas linguísticas, nem pela enunciação monológica isolada, nem pelo ato psicofisiológico de sua produção, mas pelo fenômeno social da interação verbal realizada através da enunciação. (BAKHTIN, 1992, p. 123). 
Nesta visão, o autor coloca a língua como um sistema fechado de signos para uma determinada finalidade comunicativa, aberta à variação da linguagem que impõe modificações, fazendo emergir novas expressões, signos e formas comunicacionais. A "linguagem não é um mecanismo fixo, fechado, e está em permanente mudança, podemos dizer, novos tipos de linguagens, novos jogos de linguagem, surgem, outros são esquecidos" (WITTGENSTEIN, 2005, p. 27).

Para Saussure (1989), o espaço-tempo influencia na construção da linguagem, tendo em vista que:

A cada instante, a linguagem implica ao mesmo tempo um sistema estabelecido e uma evolução: a cada instante, ela é uma instituição atual e um produto do passado. Parece fácil, à primeira vista, distinguir entre esses sistemas e sua história, entre aquilo que ele é e o que foi; na realidade, a relação que une ambas as coisas é tão íntima que se faz difícil separá-las. (SAUSSURE, 1989, p. 16).

Por serem mais fluídas, circunstanciais e afeitas à dinâmica do tempo e do espaço em sua configuração contextual, as linguagens apresentam variações que são consensualidades em campos comunicacionais, organizados com definição de limites e fronteiras.

Segundo Gadamer (2002, p. 175), foi através dos “estudos de Humboldt que a linguagem adquiriu o estatuto de filosofia ou ciência da linguagem". Como seu objetivo era investigar os idiomas dos diferentes povos, foi possível admitir que culturas diferentes possuam a mesma faculdade de organização gramatical e sintática, bem como que a ciência da linguagem, como qualquer outro fator préhistórico, representa a pré-história do espírito humano.

A linguagem, em sentido estrito, seria entendida como "abstração inobservável em si mesma; nem língua, nem fala, revelando-se nelas pelo caráter criativo, inovador, que induz a que não exista fixidez de sentido nas formas verbais" (DUARTE, 2005, p. 36). De acordo com o dicionário Semiótica, a linguagem é um objeto do saber, não sendo tal objeto definível em si, mas apenas em função dos métodos e dos procedimentos que permitem sua análise e construção. Duarte 
(2005) traz a linguagem como uma forma de expressão na produção e uso dos signos, onde:

Por vezes linguagem vira sinônimo de comunicação, às vezes de língua, sendo que a primeira é uma função da linguagem e a segunda uma contenção que delimita sistemas normativos, historicamente determinados. No entanto, a linguagem, enquanto potência humana e produzir e manipular signos, atravessa e transforma tanto as formas de comunicação, quanto as normas e os códigos linguísticos. (DUARTE, 2005, p. 36).

Pode-se dizer, assim, que o Geozine tem uma intenção comunicativa, porque é uma linguagem criada para transitar entre linguagens em um mesmo objeto. Da mesma forma, insere-se no espaço educacional para desafiar o docente a experimentar as variações dos códigos na interpretação sobre um mesmo fenômeno. Por conseguinte, a interpretação requer do intérprete a capacidade de também agir como interlocutor, o que torna o Geozine um exercício importante para a práxis didático-pedagógica.

A comunicação é um ato intrínseco do processo linguístico, por meio do qual as informações se deslocam e são aprisionadas aos códigos que se estabelecem entre emissores e receptores, pois a comunicação é um tipo de atividade social que envolve a produção, transmissão e recepção de símbolos e implica na utilização de vários recursos (THOMPSON, 2011).

Foi observado que, no processo comunicativo, existem aspectos importantes: um conjunto de símbolos, regras e combinações que promovem o ato de se comunicar, trocar e se expressar. Todavia, pode-se pensar o Geozine como um campo de intermediações entre linguagens que se formam fora da linguagem do ensino de Geografia. É neste ponto que, ao buscar "fora" para entender o que está "dentro", faz deste ato uma potência criativa para ensinar Geografia, considerando o Geozine como linguagem prática e didática.

Para Thompson (2011), pensar no ato de se comunicar está ligado diretamente ao indivíduo enquanto ser social, tendo em vista que a construção de signos, de símbolos e de formas de expressões é construída no dia a dia citadino e de vivência social. Os meios de comunicação são uma importante ferramenta de 
desenvolvimento e produção desse sistema de símbolos, desempenhando um grande papel na disseminação e produção dos sistemas simbólicos na construção do ato de se comunicar:

O Geozine surge dentro de uma era onde a informação virtual, a integração do conhecimento e a facilidade de acesso produzem diversas formas de expressão, sentimentos e símbolos. Entretanto, ainda é necessário atribuir um prolongamento sobre a linguagem, mas agora voltado para o ensino da Geografia Escolar, partindo da compreensão que linguagem e comunicação denotam de simbologias, signos e formas de expressão, tendo como finalidade a intenção comunicativa.

É nesta perspectiva linguística que consubstancia para o desenvolvimento das ciências, facilitando as formas de compreensão, facilitação e mobilização dos saberes científicos. Estabelecer o elo entre linguagem e ensino provoca passagens por diálogos multidisciplinares. Para o ensino de Geografia, esses diálogos dão lugar às significações e às formas de expressões das diversas leituras possíveis de um fenômeno. Destes diálogos, a Geografia torna visível os fenômenos do espaço, revelando os momentos das passagens, das transformações das coisas, dos objetos e das sociedades.

A compreensão da dimensão espacial na dimensão das significações infere que:

[...] os fenômenos, para existirem, possuem uma dimensão espacial que influencia diretamente a sua existência - ou, em outras palavras, todas as coisas, quando mudam de lugar, mudam igualmente de significado para si e para as demais - isto é, todos os fenômenos possuem uma "geograficidade" e é dela que falamos quando queremos identificar o significado de cada coisa (ou processo) estar (ou se realizar) num dado lugar. (SANTOS, 2007, p. 11).

Dessa forma, são os lugares que conferem vida aos significados, onde as formas de expressão dão novos enfoques para o objeto (o conhecimento). As “significações nascem no movimento entre o 'cá' e o 'lá' em função de contextos e usos. Todo signo, sozinho, parece morto. O que lhe confere vida? - Ela está viva no uso" (WITTGENSTEIN, 2005, p. 173). A linguagem e o ensino da Geografia se apresentam como uma ferramenta repleta de significações, moldadas a partir de 
cada situação e de cada lugar, na forma didática do professor e sua intencionalidade na utilização de um determinado tipo de linguagem, ao buscar, testar e ressignificar.

Nesses termos, "a linguagem se adquire estimulando, ensinado, procurando o input adequado para cada situação; perseguindo palavras sob o critério de clareza ou facilidade" (DUARTE, 2005, p. 33). Em complementação, Santos (2007) afirma que:

\footnotetext{
A linguagem geográfica assim se territorializa enquanto pensamento, ela pode ser expressa de diferentes formas, podendo ser visual, sonora, simbólica, tátil, gestual, fotográfica, cartográfica etc., mas sempre foca na interpretação da forma espacial dos fenômenos vivenciados. (SANTOS, 2007, p. 23).
}

Com isto, o ensino de Geografia passa a ser "agenciado" por essas linguagens, dentre elas, o Geozine. A principal finalidade das linguagens, no ensino, está no estabelecimento de significações, no transpor comunicativo entre conhecimento geográfico e sua diluição sob uma linguagem. Portanto, a linguagem é a maneira que o docente consegue trazer em seu fazer pedagógico as suas limitações internas (quando se fala do fazer pedagógico do professor) e externas (no que diz respeito ao ensino e aprendizagem do aluno).

Isto implica dizer que estratégias de comunicação que englobam as linguagens no ensino de Geografia, quando adequadamente utilizadas, permitem melhor aproveitamento no processo de ensino e aprendizagem, maior participação e interação aluno-aluno e professor-aluno. Entretanto, é necessário ressaltar algo característico das linguagens: "possuem códigos e seus artifícios de representação, que precisam ser conhecidos por professores e alunos com conteúdo geográficos" (PONTUSCHKA; PAGANELLI; CACETE, 2009, p. 216).

O sentido e a finalidade da linguagem dizem respeito a sua identificação, em que, no mundo atual, é possível encontrar uma ampla diversidade de linguagens, em contextos marcados por uma infinidade de informações. "A sociedade é cada vez mais uma sociedade da informação (...), é a escola, nesse contexto, que cumpre papel importante ao apropriar-se das várias modalidades de linguagens como 
instrumento de comunicação promovendo a aprendizagem" (PONTUSCHKA; PAGANELLI; CACETE, 2009, p. 261).

Em suma, foram observados o grande campo teórico que a linguagem Geozine abarca em sua construção teórica e seus aspectos metalinguísticos que fazem este produto didático para o ensino da Geografia Escolar. Muito além disso, é um objeto transitivo dotado de saberes, símbolos, signos, atos comunicacionais e elos de aprendizagem. Ainda assim, o processo teórico da linguagem Geozine requer uma prática empírica, material, na produção de ações, noções e compreensões para as lacunas que irão surgir no percurso teórico/empírico deste produto didático.

\section{POR QUE UMA LINGUAGEM GEOZINE?}

A linguagem crítica, a estruturação por meio do uso de materiais simples e o apelo à criatividade para veicular ideias foram os desencadeadores para se estabelecer um elo do Fanzine com o ensino de Geografia. Essa aproximação resultou na cunhagem do Geozine, por vezes compreendido como prática e incompreendido como conceito, mas sempre utilizado como estratégia para mobilizar no ensino de Geografia. São lacunas que persistem e que fazem aprofundar, compreender e refletir. É certo que cabem mais questionamentos do que respostas.

O início dessa história está nas inquietações do pesquisador e professor Antônio Gomes em sua dissertação de mestrado, desenvolvido junto ao Programa de Pós-graduação Profissional em Geografia da Universidade Federal do Rio Grande do Norte. Silva (2018), em sua pesquisa, retrata a profissão do professor, frente às problemáticas diárias no saber-fazer que são vistas:

A profissão de professor está nesse contexto da inquietação criativa, seja, na universidade que exige a vivência no Ensino, Pesquisa e Extensão, seja nas experiências na escola, que implica lidar com uma complexidade de sabres, dúvidas, imprevisões provenientes de campos disformes, seja na condição de um ser limitado de quem é solicitada uma atuação ilimitada. (SILVA, 2018, p. 86). 
Dessa perspectiva, o autor reflete sobre o seu saber-fazer e a busca por novos horizontes e formas de expressões. Dedica-se a elaborar uma proposta metodológica experimental com inspirações no Fanzine, criando o Geozine como uma possiblidade para ensinar Geografia. Em sua pesquisa, volta-se aos conteúdos sobre região no ensino fundamental (anos finais). Para ele, trabalhar com linguagens no ensino da Geografia está relacionado aos processos:

[...] de amadurecimento teórico sobre a Geografia escolar [que o instigou] para sistematizar uma proposição metodológica que pudesse explicitar essa experiência como linguagem didática, proporcionando uma reflexão que pudesse ampliar as estratégias para ensinar. (SILVA, 2018, p. 88).

Portanto, o Geozine é um produto que também surge para responder lacunas, através da experimentação desta estratégia didática, utilizando os aspectos significativos do aluno para construção de uma ponte que interligue os conteúdos geográficos à realidade holística e de vivências.

Sobre o Geozine como um objeto didático, o autor o associa a uma linguagem que se transforma no campo da experimentação e na ampliação de horizontes no âmbito do ensino de Geografia. Diante disto, toma-se como base a ideia de Silva (2018) e propõe-se o desafio para esta dissertação em ampliar a discussão, verticalizando o diálogo com outros autores e buscando compreender o Geozine enquanto uma linguagem, pois é preciso refletir a respeito do percurso metodológico e das lacunas ao longo do caminho teórico.

Nessa condição, há a pretensão de adentrar ao campo da linguagem, estabelecendo uma interface com o Geozine e buscando acentuar a sua característica como uma metalinguagem que se organiza pelo trânsito entre diferentes expressões a fim de responder: por que uma linguagem Geozine? Primeiramente, é necessário buscar a imensidão teórica do campo científico que é a linguagem, com a finalidade de criar meios que propicie o entendimento conceitual do Geozine.

É sabido que as relações do homem com a natureza ocorrem por meio da criação de códigos que, simultaneamente, decifram e recodificam o mundo vivido 
e percebido. Nesse mecanismo de codificação e decodificação, pode-se entender como uma estratégia de compreensão e sobrevivência da espécie humana em seu processo de humanização. Ademais, impõe-se como conteúdo de sua singularização ou especialização sociocultural e espacial ramificada por extensões da linguagem e da comunicação.

A compreensão do Geozine passa, portanto, pela reflexão sobre linguagem e comunicação, sua interferência na organização das vivências, especialmente aquelas relacionadas ao contexto didático-pedagógico escolar e do ensino de Geografia. Denominar o Geozine como uma linguagem didática é dizer que ele se comporta como uma estratégia pedagógica voltada para o ensino da Geografia Escolar, visto que é uma "mediação dialética do professor e, portanto, o de propiciar a atividade cognitiva do aluno por meio de encaminhamentos metodológico para que esse aluno construa conhecimento e desenvolva capacidades e habilidades cognitivas" (CAVALCANTI, 2010, p. 59).

O Geozine tem como principal característica o elo com diferentes linguagens na sua criação que funciona como uma espécie de metalinguagem. Em outras palavras, é uma linguagem que se alimenta de outras "linguagens" para estruturar a sua própria, tornando-o um objeto único pelo uso dessa pluralidade, onde o “potencial que há no Geozine, enquanto linguagem e comunicação se dá no processo de construção, em que o sujeito precisa, minimamente, entendê-lo e, nesse sentido entra o professor para criar as condições iniciais" (SILVA, 2018, p. 93), para mobilizar música, fotografia, mapas, literatura, texto científico, dentro outros.

Diante disso, o Geozine é um elo que se liga a diversos elementos linguísticos que, como o próprio, contêm símbolos, signos e códigos. Apesar de ser plural, apresenta um sistema organizativo fechado, uma vez que, por se tratar de uma linguagem didática, deve apresentar delimitações em sua construção, sejam teóricos e empíricos (enquanto exemplificação e materialização). Sendo assim, sua elaboração está relacionada a uma intencionalidade voltada ao ensino e à 
aprendizagem, o que implica dizer que a sua criação está vinculada à dimensão dos conhecimentos geográficos.

O Geozine, entre tantas características, tem o ineditismo na sua elaboração, ou seja, nenhum produto será igual ao outro, porque parte do mundo das ideias, da criatividade, do olhar tocante do indivíduo e da problematização das coisas reais. A partir daí, ao se materializar, o Geozine surge como um elo que atrai diversas outras linguagens, seja a música, a fotografia, os poemas, as gravuras e outros. Como aponta Silva (2018, p. 93):

A primeira abordagem passa pela a originalidade artesanal, tendo em vista que, um Geozine não será igual ao outro, mesmo que feitos pela mesma pessoa. Serão impressas "marcas" e características de quem o produziu, sendo desta forma um meio pelo qual podemos mensurar o nível de entendimento.

Portanto, o Geozine é uma linguagem original, materialmente falando "manual": uma tela em branco, onde o pintor derrama toda a sua criatividade, criando, em sua obra, códigos e signos que servirão como uma ponte comunicacional para a compreensão "todo", mas que poderão ser vistas as marcas e a intencionalidade de quem o fez. Dessa forma, Silva (2018) também aponta uma outra abordagem linguística acerca do Geozine, por meio da qual:

O mais importante é o trabalho intelectual e o exercício do pensamento. Consiste num momento em que a criatividade é o combustível indispensável, chega a ser uma produção artística, de estética que imprimem singularidades, além de aprender o que o se espera do sujeito, na verdade, mostrará os seus mundos. (SILVA, 2018, p. 94).

O Geozine, enquanto linguagem didática, é uma estratégia que está em constante movimentação, buscando romper com o "ensino estatístico" para o ensino dos conteúdos geográficos a partir da visão metalinguística, uma vez que a criatividade humana faz parte do processo linguístico e comunicacional. Neste sentido, Straforini (2006) aponta a necessidade desse movimento didático na Geografia escolar: 
A Geografia, necessariamente, deve proporcionar a construção de conceitos que possibilitem ao aluno compreender o seu presente e pensar o futuro com responsabilidade, ou ainda, preocupar-se com o futuro através do inconformismo com o presente. Mas esse presente não pode ser visto como algo parado estático, mas sim em constante movimento. (STRAFORINI, 2006, p. $51)$.

A concepção prática do Geozine, enquanto linguagem, perpassa também no caminho intencional, pois sua construção material requer se apropriar, primeiramente, de um "mote" que são os conteúdos e saberes geográficos; em segundo, está na concepção linguística utilizada na elaboração do objeto didático, por meio do qual o Geozine faz o "contrabando" das ferramentas, das metodologias e das linguagens. Assim, surge um produto didático dotado de habilidades e intencionalidades comunicativas. Conforme aponta Silva (2018, p. 93):

No Geozine há combinações de áreas distintas do saber. Quando o aluno está selecionando uma imagem para representar uma dada característica da região, ele já acionou e estabeleceu mentalmente a conexão com a palavra. A escolha da representação não é aleatória, então, o conceito em si, tem importância a partir da ligação da palavra.

A linguagem Geozine tem, nas combinações, o elemento principal, a ponte capaz de ressignificar o objeto metalinguístico. É válido ressaltar que as conexões surgem na sua construção, a depender da intencionalidade de quem elabora, enquanto uma metodologia didática, e, como todo ato criativo, o "produto final" é desconhecido. O Geozine, como proposição didática, surge como mais um auxílio para o ato do ensinar Geografia, na falta de materiais didáticos e estratégias que dificultam a práxis educacional. Logo, isso justifica o fato de o Geozine ser direcionado à experimentação e ao desenvolvimento de habilidades do professor, pois dele requer uma ação didática para desenvolver, no educando, a percepção temática a ser estudada e a visão de mundo do aprendiz.

O uso e a intenção do Geozine, no fazer didático do professor, também se comporta como um elo e não como uma finalidade. É necessário que o professor introduza a linguagem como forma de unir os conhecimentos teóricos e as teias geradas durante as aulas. Dessa forma, cabe ao professor guiar o processo, 
sabendo, de antemão, que é preciso manter o sentido pedagógico, mesmo tendo o conhecimento de que o produto será baseado em diversas percepções.

A mediação, neste processo, é de grande importância. Imaginemos um cenário em branco, onde o que prevalece no meio são as palavras "lugares", "paisagens" e "Taipu". A imagem que o indivíduo está criando são acepções sobre essa tríade, organizando palavras ou frases, mas que são insuficientes para explanar na oralidade. Para isso, colocamos alguns dispositivos em torno das palavras, como imagens, frases, músicas, poemas, jornais/notícias. A função destes dispositivos se afigurará em uma rede de conhecimento e, quando colocado em ação, promoverá a aprendizagem.

É assim que o Geozine se apresenta, como uma grande tela em branco que vai sendo preenchida mediante a ligação entre diferentes linguagens, promovendo um exercício metalinguístico. No âmbito do ensino de Geografia, essa experiência denota estratégias que estão em relacionar, esquematizar, ligar, criar símbolos, conexões, sentidos e materializar pensamentos e ações.

\section{A OFICINA GEOZINE NA FORMAÇÃO DOCENTE: PRÁTICAS DIDÁTICAS}

A oficina "Geozine: Construindo uma metodologia didática" surge com a proposta de prover um ambiente de formação docente aos educadores das instituições escolares da cidade de Taipu/RN. Além disso, tem como objetivo colocar em prática a linguagem Geozine como uma estratégia pedagógica que possa ser utilizada e ressignificada pelo professores, ou seja, é mais uma tentativa de propiciar ambientes de aprendizagem aos seus principais atores do ensino, os professores.

A oficina ocorreu no dia 11 de setembro de 2019 na Escola Municipal Professora Francisca Avelino, no turno matutino. Com a presença de 15 (quinze) professores do ensino básico, dentre eles os que lecionam a disciplina de Geografia. 
Para o desenvolvimento da oficina, foi necessária a organização dos materiais e insumos para a ocorrência dela.

Dessa forma, foram disponibilizadas folhas de papel A4, coleções (madeira, hidrocor e cera), tesouras, colas, exemplos de Geozine, livro/revistas para recorte, jornais e imagens dos lugares e das paisagens taipuenses.

A partir disto, a oficina foi dividida em 4 (quatro) momentos, com o intuito de transformar a oficina Geozine em um momento de trocas e de diálogos de professores para professores. Portanto, o objetivo não era apontar "erros", mas construir cenários possíveis e tangíveis de serem alcançados.

O primeiro momento, denominado de "as linguagens no ensino de Geografia escolar", tinha por objetivo refletir sobre as linguagens na Geografia Escolar, o ensino da Geografia no contexto atual e o perfil do professor na era das Tecnologias da Informação e da Comunicação (TICS). Para este momento, buscouse trabalhar, metodologicamente, com uma abordagem teórica construtiva e dialogada sobre as linguagens no ensino da Geografia, iniciando com uma dinâmica intitulada de "quem é você professor" e, em seguida, uma enumeração de questionamentos acerca do perfil do educador na atualidade. Além disso, foi criado um espaço de debates com a finalidade de trocas de saberes e acepções sobre a Geografia Escolar.

A construção desta primeira parte foi estruturada a partir das acepções dos docentes participante da oficina, sendo todos os momentos registrados por meio de vídeos e fotos. A primeira parte foi iniciada com a apresentação do mediador e com uma abordagem acerca da importância da Oficina Geozine e seu objetivo central que está na experimentação desta metalinguagem. Dessa forma, foi apontada a importância desta pesquisa que está sendo realizada na cidade de Taipu e, em especial, na instituição Francisca Avelino. A referida importância se dá pelo fato de ser um espaço escolar de grande vivência estudantil para o autor.

A primeira ação da oficina foi a realização de uma dinâmica que consistia em escolher o nome de uma música ou uma frase que caracterizasse o participante 
enquanto professor. Este momento tinha por finalidade estreitar as relações interpessoais e promover diálogos iniciais.

A dinâmica possibilitou aflorar a imaginação dos professores através da letra de uma canção ou frase que trouxesse sua figura enquanto professor. Os educadores se debruçaram em torno das principais barreiras de ser professor na atualidade. Dentre os trechos citados, encontra-se o da professora Adriana, que trouxe uma frase de sua própria autoria "Eu acredito na força do professor, um guerreiro sem espada, sem faca, foice ou arma, só com um giz na mão segurando o amor", em que, para ela, o professor carrega consigo a maior arma que pode mudar a realidade do aluno, de uma sociedade e de uma nação: a educação. Já a professora Solange diz que ser professor é "viver e não ter vergonha de ser feliz (...), cantar e cantar". Nesta gama de expressões de vivências e acepções sobre a figura do professor, foi iniciada a Oficina Geozine.

Logo após esta dinâmica, deu-se prosseguimento à oficina com alguns questionamentos iniciais com o intuito de refletir a respeito de alguns "préconceitos" que a sociedade e os próprios professores indagam sobre a figura do educador, a saber: qual deve ser o papel do professor na educação? Qual a importância de um professor para a sociedade? Qual a função da escola? Qual o perfil do professor ideal? O problema está no ensino ou na aprendizagem? O que é um bom professor? O objetivo central era refletir sobre qual professor se configura na atualidade, tendo em vista que foi necessário entender com quais professores estamos falando e qual a figura do educador nesta era informacional.

Diante disto, a discussão seguiu para a compreensão sobre a era das Tecnologias de Informação e Comunicação, suas implicações no perfil do professor e na figura do aluno, ressaltando que as TICS, na educação, surgem com o intuito de facilitar o acesso à informação. No entanto, o âmbito da escola, enquanto instituição formadora, provocou mudanças estruturais ao professor e ao aluno como figura central do processo do ensino e aprendizagem, ainda que o educando venha dotado de informações em massa, muitas vezes fragmentadas. 
Em seguida, após a reflexão da tríade escola-professor-aluno, procurou-se fechar a discussão com a indagação: qual o maior desafio de ser professor? Sem dúvidas, foram momentos de exposições de sentimentos e acepções da figura do aluno que temos na escola. Dentre tantos questionamentos, os educadores expuseram a seguinte frase: "o principal desafio de ser educador está no ato de ensinar um aluno que não quer aprender". Este é um dilema que percorre a realidade educacional do Brasil e do professor ao buscar estratégias, linguagens e metodologias que auxiliem a aprendizagem do discente.

Diante disto, partiu-se para a discursão sobre as linguagens no ensino da Geografia, elucidando a figura do professor no processo do ensino e da aprendizagem e na necessidade de se trabalhar com estratégias didáticas. Falar de estratégias é ligar-se ao mundo das linguagens didáticas, partindo da premissa conceitual sobre o que é linguagem, trazendo para os professores exemplos linguísticos e comunicacionais (cartografia, cinema, fotografia, desenhos, música, etc.) que os próprios utilizam, mas não denominavam como um recurso linguístico dotado de comunicação.

Um dos docentes participantes da oficina, ao compreender as conceituações sobre a linguagem, indagou "por que trabalhar linguagens no ensino das ciências escolares?". Logo, como resposta, destaca-se que o uso das linguagens está em trazer o educando para o círculo da aprendizagem, das descobertas, das curiosidades, das significações das coisas e do mundo que o rodeia. Neste meio, qual seria a função do geógrafo-educador? Está, portanto, em despertar nos alunos a importância dos aspectos sociais, em orientar a leitura geográfica do espaço e interferir na reflexão da construção do conhecimento, ampliando sua percepção sobre o mundo que o cerca.

É, portanto, a figura do professor responsável pela busca constante de novas estratégias de ensino para trabalhar no processo da aprendizagem. Percebe-se que, muitas vezes, o docente acaba deixando de lado a função do professorpesquisador, fato que corrobora a importância de lembrar que "um bom professor 
não se faz apenas com teorias, mas principalmente com a prática e o estímulo a uma ação-reflexão-ação e a uma busca constante de um saber mais e de um fazer melhor" (PAIVA, 2003).

O segundo momento da oficina de construção didática "Geozine" trouxe, como premissa, conhecer este produto enquanto uma metalinguagem didática, bem como: a compreensão do Geozine enquanto sua estruturação e elaboração; seus objetos do conhecimento e habilidades no contexto da produção; e como sua construção consegue ativar em quem o elabora. Por fim, teve o objetivo, ainda, de explorar as noções do lugar e da paisagem taipuense através do Geozine.

Como caminho metodológico, o segundo momento buscou aproximar o professorado aos principais conceitos que norteiam a oficina, como os conceitos geográficos (lugar e paisagem), de forma que possibilitassem a compreensão da proposta teórica e conceitual. Foi nesta etapa que os participantes passaram a conhecer o que é o Geozine e quais as suas principais características, fazendo uso de uma linguagem visual simples e mostrando o produto didático a partir da construção de um quebra-cabeça dialogado. Por fim, foi elucidada a Base Nacional Comum Curricular (BNCC) e sua aproximação com o Geozine, criando uma estruturação prévia acerca dos objetos do conhecimento e as habilidades atreladas a este. Esta etapa da oficina também trouxe o Geozine como uma das estratégias didáticas que o professor na atualidade pode buscar em seu fazer pedagógico para trabalhar com seu educando.

Tratando do termo Geozine, foi necessário esclarecer, neste momento, sua nomenclatura, pois, segundo os professores, o termo "Geozine" chamou atenção e despertou curiosidades, sendo um dos fatores que levaram alguns educadores a participar. A estrutura desta etapa se iniciou a partir da exposição teórica do Fanzine até chegar ao Geozine, sendo o Fanzine já conhecido por alguns docentes e desconhecido por boa parte dos participantes.

Diante disto, compreende-se como Geozine "uma linguagem didática para a Geografia escolar, voltado especificamente para os conteúdos geográficos" (SILVA, 
2018, p. 90), tendo como características: sua função transitiva, as mobilizações linguísticas, comunicacionais e seu ineditismo. Contudo, para uma maior exemplificação, foi construído um Geozine virtual, utilizando as formas necessárias para sua elaboração. Além disso, foram utilizadas algumas animações, mostrando a página em branco (Figura 1) e, aos poucos, apresentando as diversas linguagens que o Geozine consegue abarcar.

Após a apresentação da pluralidade de linguagens que o Geozine consegue comportar, os educadores foram levados às principais habilidades e competências iniciais do Geozine, deixando claro que estes aspectos não são imutáveis, mas mutáveis a partir da percepção de cada docente durante a oficina e no processo da avaliação (feedback). Portanto, foram explanadas algumas competências e as principais habilidades no processo da aprendizagem. Ademais, estes aspectos foram adaptados, utilizando os conceitos propostos pela Base Nacional Comum Curricular e sua relação com o Geozine.

A principal motivação para a escolha da BNCC diz respeito à sua grande importância para a educação brasileira na atualidade. Embora a Base não seja um currículo pronto, ela funciona como uma orientação aos objetivos de aprendizagem de cada etapa da formação escolar, sem ignorar as particularidades de cada escola no que diz respeito à metodologia e aos aspectos sociais e regionais.

A partir das concepções propostas pela BNCC e tendo como foco central o Ensino Fundamental anos finais, foi proposta a construção de um quadro (Quadro 1), através do qual foi refletido acerca do Geozine no contexto propositivo com a Base, adaptando os principais aspectos para este produto didático. Sendo assim, buscou-se refletir acerca do "Geozine: Lugar e Paisagem" como a unidade temática central que são os conteúdos correlacionados ao nível de ensino. 
Figura 1 - A metalinguagem do Geozine

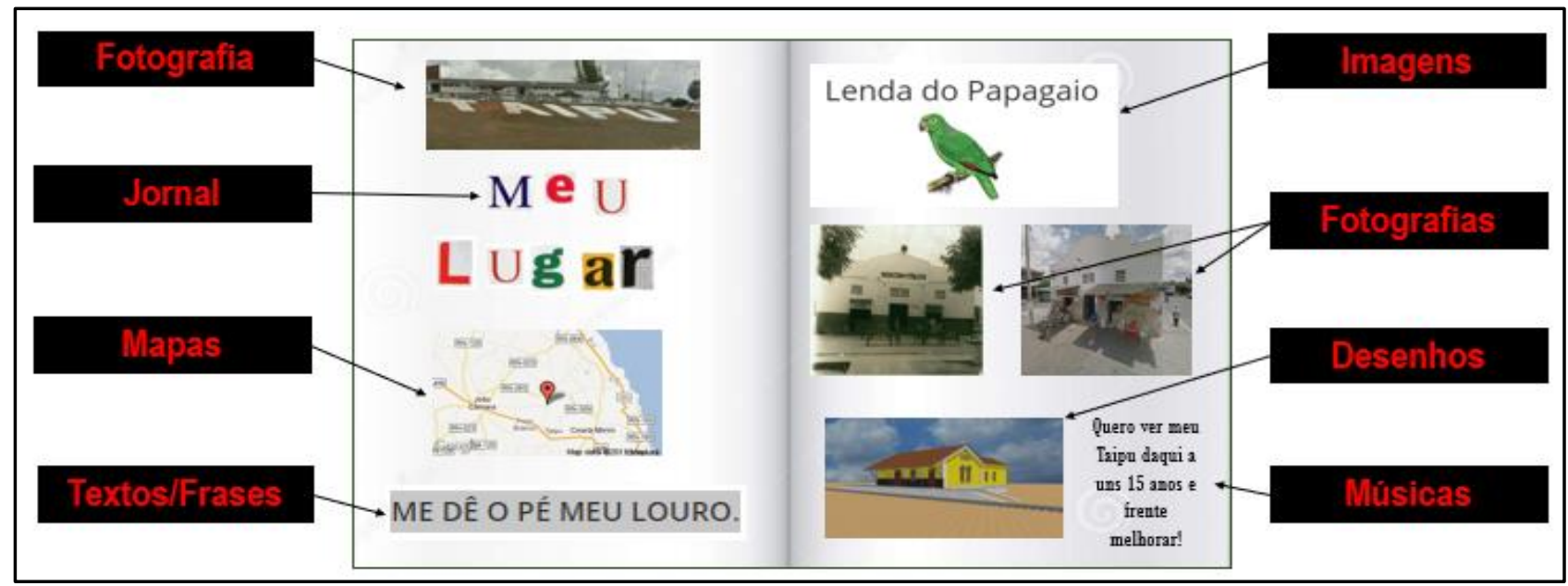

Fonte: Elaborado pelo autor (novembro de 2019).

Neste nível, foram selecionados o $6^{\circ}$ ano do Fundamental anos finais, a delimitação dos objetos do conhecimento (os conteúdos), os aspectos temáticos e, por fim, as principais habilidades que dizem respeito às aprendizagens essenciais esperadas e ativadas naquele que elabora o Geozine. O quadro, contendo o objeto de conhecimento e as habilidades, foi descrito aos professores de modo didático e com exemplificação prévia de como essa ativação ocorre no processo de ensino e da aprendizagem.

Dentre os principais objetivos do conhecimento, estão: a reflexão do Geozine enquanto uma metalinguagem e seus principais artifícios já citados nesta dissertação e o percurso transitivo deste objeto didático. Já nas habilidades, encontra-se um acervo de conhecimentos que o aluno conseguirá ativar no processo da aprendizagem, seja no acesso das diferentes linguagens (música, fotografia, imagens, poemas, etc.) até os elos comunicativos na materialização e nas acepções produzidas pelo o Geozine.

Em seguida, aponta-se, como proposta, o uso deste produto didático sob a perspectiva das noções dos lugares e das leituras das paisagens, utilizando Taipu como fonte para elaboração do Geozine, oportunizando uma reflexão sobre o lugar como centro das ações que englobam as experiências e as aspirações do homem. A paisagem pode contribuir para compreender essas inspirações através 
da alfabetização do espaço geográfico, deixando claro para os docentes que, ao estudar o lugar e a paisagem como vivência do aluno, abrem as possibilidades de um leque de opções para compreender sua realidade. Portanto, são aliados estes dois conceitos basilares da ciência geográfica ao chão de vivência dos educandos, sendo suas narrativas expressas na linguagem Geozine.

Quadro 1 - O Geozine na estruturação da BNCC

\begin{tabular}{|c|c|c|}
\hline $\begin{array}{l}\text { UNIDADE } \\
\text { TEMÁTICA }\end{array}$ & OBJETO DO CONHECIMENTO & HABILIDADES \\
\hline \multirow{5}{*}{$\begin{array}{l}\text { GEOZINE: } \\
\text { LUGAR E } \\
\text { PAISAGEM }\end{array}$} & $\begin{array}{l}\text { Compreender diversos elementos } \\
\text { linguísticos e metalinguísticos } \\
\text { didáticos-pedagógicos. }\end{array}$ & $\begin{array}{l}\text { Interpretar o uso e ativação de } \\
\text { diferentes signos, códigos e sentidos } \\
\text { metodológicos. }\end{array}$ \\
\hline & $\begin{array}{l}\text { Compreender a produção e } \\
\text { transformação dos elementos da } \\
\text { linguagem Geozine como uma } \\
\text { estratégia pedagógica. }\end{array}$ & $\begin{array}{l}\text { Identificar as características do "elo" } \\
\text { na ligação como uma pluralidade } \\
\text { metalinguística, desde os sons, } \\
\text { imagens, desenhos, escritas e dentre } \\
\text { outros. }\end{array}$ \\
\hline & $\begin{array}{l}\text { Entender as transformações } \\
\text { técnicas e tecnológicas e seu } \\
\text { impacto nos processos de produção, } \\
\text { no desenvolvimento do } \\
\text { conhecimento. }\end{array}$ & $\begin{array}{l}\text { Comparar os diferentes conectivos } \\
\text { que se afloram na medida em que } \\
\text { novas descobertas surgem, } \\
\text { ampliando e materializando } \\
\text { continuamente o produto. }\end{array}$ \\
\hline & $\begin{array}{l}\text { Utilizar os saberes interdisciplinar } \\
\text { das variadas áreas de conhecimento } \\
\text { das ciências escolares. }\end{array}$ & $\begin{array}{l}\text { Relacionar o Geozine como uma } \\
\text { linguagem transitiva, uma vez, que } \\
\text { pode ser utilizado como uma } \\
\text { estratégia pedagógica em todo e } \\
\text { qualquer tema, conteúdo ou } \\
\text { princípios geográficos. }\end{array}$ \\
\hline & $\begin{array}{l}\text { Refletir o Geozine como um material } \\
\text { didático que vai de desencontro com } \\
\text { a perspectiva educacional e } \\
\text { tecnológica atual. }\end{array}$ & $\begin{array}{l}\text { Reconhecer o Geozine na perspectiva } \\
\text { da materialização manual, e nos } \\
\text { processos didáticos de sua } \\
\text { elaboração, uma vez, que constrói } \\
\text { algo de inédito, manual e com poucos } \\
\text { recursos. }\end{array}$ \\
\hline
\end{tabular}

Fonte: Elaborado pelo autor (novembro de 2019).

É importante destacar que o desenvolvimento do Geozine foi feito sob a perspectiva das noções do lugar e da paisagem como norte na elaboração deste 
produto didático. Para isto, foi construído um outro quadro acerca das competências especificas para a Geografia, utilizando como base do $6^{\circ}$ ao $9^{\circ}$ ano e trabalhando o Geozine com as questões do lugar e da paisagem, dentro de uma proposição adaptativa com a Base Comum Curricular.

\subsection{CONSTRUINDO UM GEOZINE: MATERIALIZANDO O OBJETO DIDÁTICO}

É no terceiro momento que ocorreu a construção e experimentação dos Geozines elaborados pelos professores, a partir das noções dos lugares e da exploração das paisagens da cidade de Taipu. A partir disto, foi explanada a confecção deste produto, seguindo como parâmetro a proposição feita por Silva (2018), em que primeiro foi colocado um quadro geral dos materiais necessários (já disponibilizados), uma folha de papel A4 (base para a construção do Geozine) e exemplos de Geozines (Figura 17) para observarem, folhearem e indicarem caminhos para uma posterior construção.

Dentre os Geozines disponíveis, estavam exemplos criados por professores de outras "oficinas Geozines" aplicadas em instituições públicas e privadas. Todavia, também estavam presentes produtos elaborados por alunos de diversas faixas etárias e níveis de ensino, do fundamental ao nível médio, e exemplares aplicados na disciplina de Psicopatologia na Educação, em uma turma de pós-graduação em Psicopedagogia Clínica.

Após a explanação dos passos para a elaboração do Geozine e a distribuição dos pequenos folhetos já prontos para serem preenchidos com liberdade criativa de cada professor, foi colocada a proposta temática do Geozine e seu elo com as noções dos lugares e a leitura das paisagens taipuense. Para elaborar o Geozine, foram passadas as seguintes informações: dobrar a folha em quatro partes (tendo um total de 8 lados); a primeira página é destinada à capa contendo um título (de acordo com o tema); em cada lado, será desenvolvido o enredo usando imagens, 
desenhos, letras, poemas, frases e outras linguagens. Tudo a partir das percepções, da criatividade e da liberdade do autor.

Como a temática para os docentes da Oficina Geozine, tinha o intuito de elucidar os lugares e as paisagens da cidade de Taipu, seguindo o tema: "Nas paisagens taipuense, sinto o cheiro dos meus lugares de vivências". A partir disto, os docentes se encaminharam à "ala" dos materiais (Figura 18) que estavam disponíveis para uso, durante a elaboração do Geozine. Dentre os recursos disponíveis, estavam diversas imagens que elucidavam os lugares e as diversas paisagens taipuenses, sendo um momento de aproximação com suas vivências diárias.

Figura 2 - Professores experenciando os materiais e as imagens de Taipu.

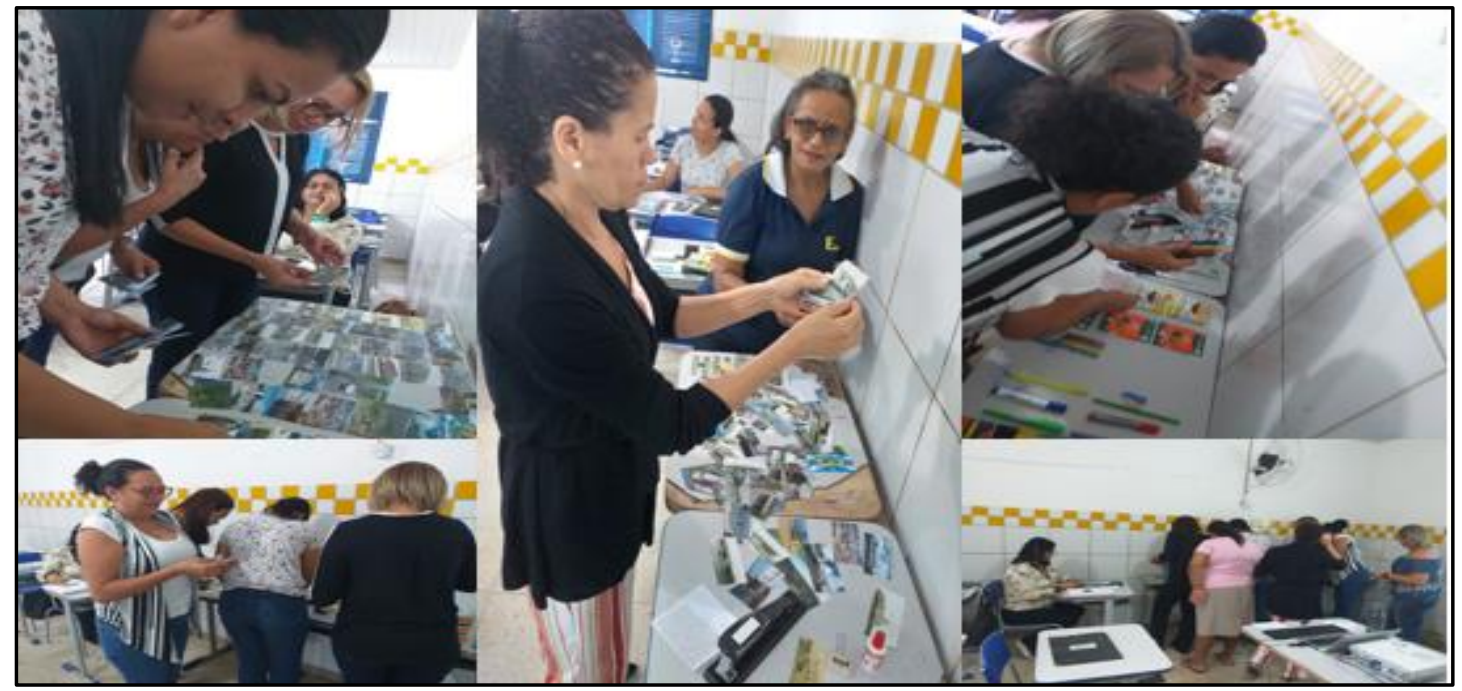

Fonte: Acervo do autor (setembro de 2019).

No momento da escolha das imagens, era perceptível a animação dos professores ao observarem as figuras. Foi possível ver que suas vivências sob o "chão" da cidade taipuense estavam eclodindo naquele momento com as lembranças citadinas do ontem e do hoje. Isto foi percebido na fala da professora Dalvaci ("passava todos os dias nesta ponte para chegar até a escola aqui em Taipu") e nas lembranças de Maria de Jesus ("venho por essa estrada todos os dias no ônibus da Cabral e nunca parei para ver a beleza dessa paisagem"). 
Figura 3 - Professores produzindo o Geozine.

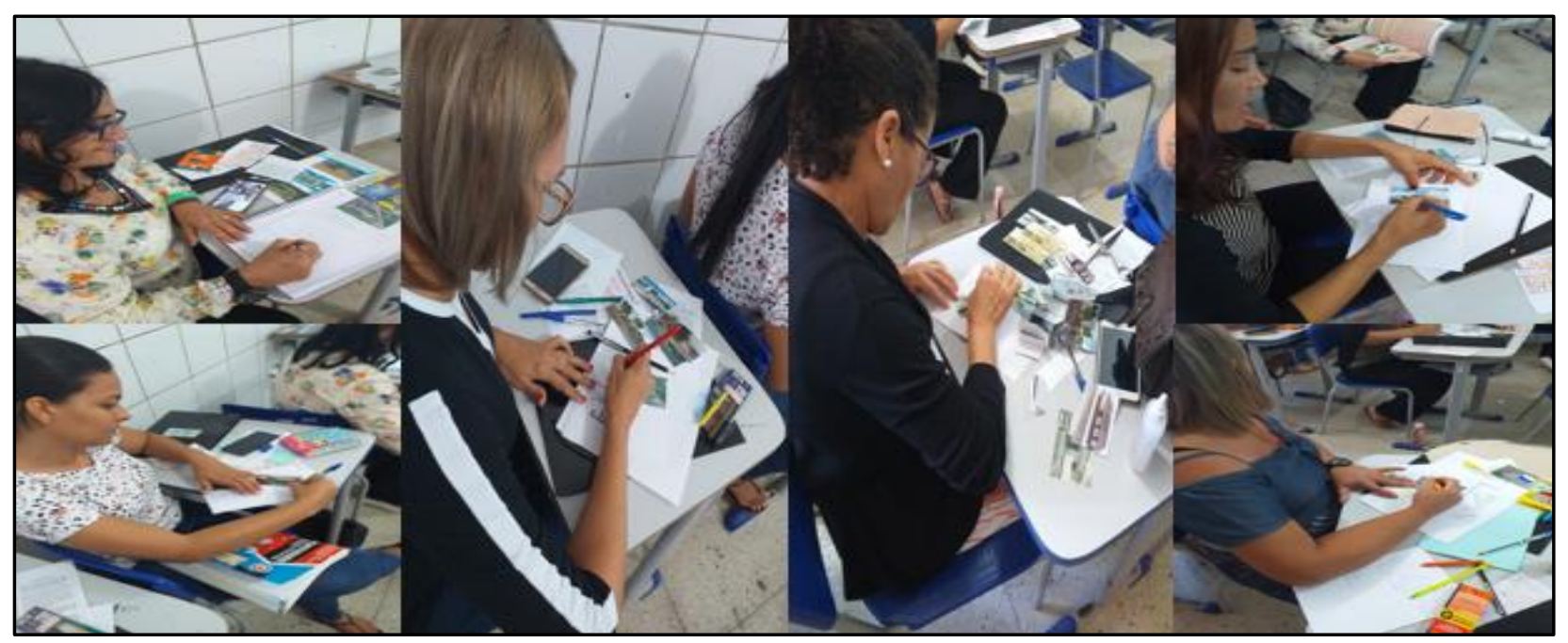

Fonte: Acervo do autor (2019).

Com os materiais, os professores começaram o processo de elaboração dos Geozines, debruçando sobre esta ferramenta didática as percepções, as vivências, as experiências dos lugares e das paisagens de Taipu. Na Figura 4, destacam-se as produções desenvolvidas pelos professores participantes e os Geozines, sob o olhar e a perspectiva do lugar e da paisagem taipuense. É perceptível que, durante a realização deste momento, os docentes puderam relembrar momentos que marcaram suas vidas: os lugares, as ruas e as marcas nas paisagens taipuenses.

No último momento da oficina, buscou-se avaliar o Geozine como linguagem e estratégia didática. Após todo processo de compreensão e experimentação do produto didático, procurou-se analisar os "feedbacks" dos professores acerca das suas percepções, refletindo sobre as habilidades e as competências que o recurso consegue abarcar; identificando vantagens e desvantagens na elaboração do material; e apresentando sugestões para o desenvolvimento do Geozine. 
Figura 4 - Geozines produzidos pelos professores.

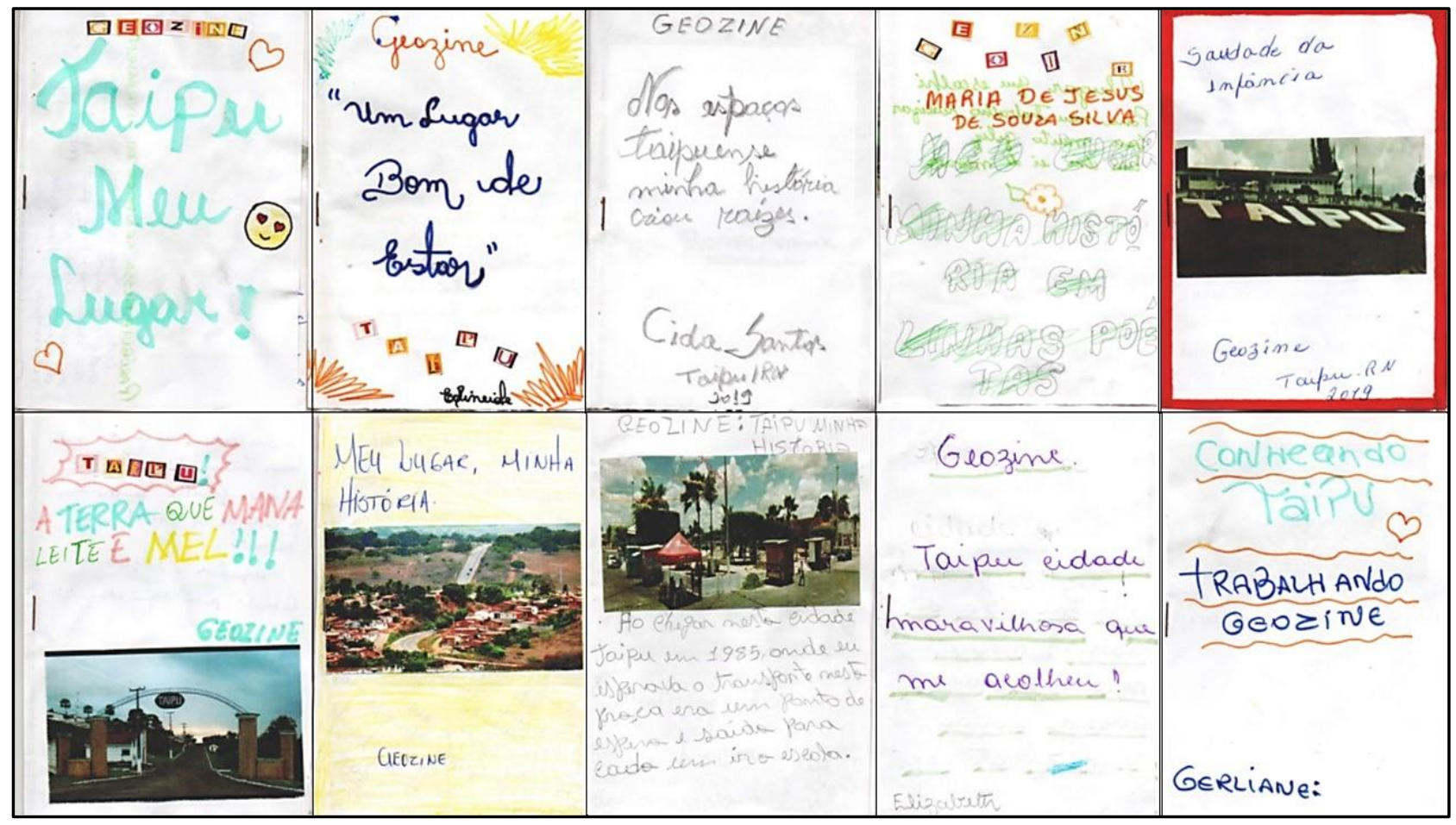

Fonte: Acervo do autor (setembro de 2019).

Os professores apresentaram seus Geozines, exemplificando suas construções e intencionalidades na elaboração do produto didático. Essas explanações estão presentes nas análises dos Geozines do "terceiro momento". Durante as explicações, foi possível ver a emoção em contar um pouco de sua história, em compartilhar saberes, momentos importantes que ficaram marcados nas paisagens e os lugares que são simbólicos em seu cotidiano. Somente após a conclusão das apresentações, os questionários que caracterizam este quarto momento foram entregues para seu preenchimento.

Os professores expressaram, quando questionados sobre uma desvantagem no uso do Geozine em seu fazer pedagógico, a falta de material ou insumos, como, por exemplo, coleções, livros de recorte, revistas e outros. Em continuação, afirmaram que, mediante a situação educacional vivida pelas instituições de ensino da cidade, as escolas apresentam graves problemas físicos e pedagógicos relacionados aos materiais informacionais e didáticos. Ainda acrescentam que, embora a "barreira" acima apresentada fosse um impedimento ao trabalhar com 
Geozine, o produto didático se apresentou como uma estratégia que dá diversos cenários possíveis para sua utilização por conter diversos instrumentos e elementos linguísticos.

Quando questionados dos professores a respeito do Geozine dentro do processo do ensino e da aprendizagem, elencaram algumas potencialidades desta estratégia em sala de aula listando diversos aspectos importantes, a saber:

- A socialização com o grupo e a concepção do produto;

- A melhoria da aprendizagem e surgimento de novas ideias;

- A concentração dos alunos e o desenvolvimento da criatividade;

- O desenvolvimento da prática que eleva o nível de concentração e que instiga a imaginação na elaboração do Geozine;

- A possibilidade de ser utilizado em todas as áreas do conhecimento;

- A compreensão dos diversos elementos linguísticos e metalinguísticos didáticos-pedagógicos;

- Em despertar no aluno o interesse para desenvolver habilidades e o raciocínio logico;

- Permite que o aluno vivencie na prática a elaboração e criação de suas próprias ideias, através do registro.

- Desenvolve a criatividade, habilidade e concentração, produzindo uma aprendizagem significativa.

Diante disto, pode-se observar que a oficina Geozine trouxe uma pluralidade de novos horizontes aos educadores, uma vez que a ferramenta didática, na visão destes atores sociais, apresenta mais vantagens enquanto recurso pedagógico aliado à prática docente. Ainda no processo avaliativo, os professores refletiram sobre o quadro do Geozine na estruturação da BNCC, em que, com is to, propiciou um momento de discussão sobre os objetos de conhecimento e habilidades, pois, durante este momento, o professorado optou por construir um novo tópico ao quadro, sendo o objeto do conhecimento "incentivar a escrita, leitura, no uso da criatividade, coordenação motora, reflexão referente ao tema, descobrindo as 
transformações do espaço-tempo", tendo como habilidade "desenvolver diferentes técnicas como a leitura, a escrita, o desenho, a coordenação motora e outros".

É importante destacar que, neste momento de avaliação da oficina, alguns educadores expuseram que desconheciam a nova proposição da BNCC (competências, unidades temáticas, objetos do conhecimento e habilidades), o que dificultou um pouco o entendimento coletivo, mas foram necessárias colocar práticas para uma melhor compreensão.

Por fim, houve um questionamento final acerca do Geozine como uma estratégia metodológica viável para o ensino de Geografia, em que os educadores expuseram diversos aspectos sobre o objeto didático, como:

- Acredito que é viável desenvolver o Geozine utilizando diferentes linguagens, como mapas, começando do nosso Taipu e a região Nordeste.

- Sem dúvidas, o Geozine faz o discente se aprofundar no assunto, estudando com bastante empolgação, chegando a expor todas suas opiniões a partir da liberdade de expressão e da sua criatividade.

- Tendo em vista que esta estratégia abrange um leque magnífico metodologicamente falando, provendo uma aprendizagem significativa e real para um mundo de conhecimento que o aluno tem a sua disposição. Além disso, é uma ferramenta inovadora na prática educacional.

- O que mais chama atenção no Geozine é a quebra de paradigmas, pois fazem os alunos saírem da rotina daquele "só faz copiar". Além disso, é uma forma do educando "vergonhoso" se expressar da melhor maneira que ele deseja.

- Um dos grandes fatores que me encantou é a promoção da pesquisa, a recordação de fatos ocorridos, como também a criação de ideias que fluíram para a construção do Geozine. Um produto didático excelente ao desenvolver a prática educativa com material concreto e criado pelo o próprio aluno. 
Em suma, a oficina Geozine ${ }^{1}$ despertou, nos educadores, um sentimento de pertencimento, uma chama reacendeu, pois possibilitou o resgate de memórias, lugares e paisagens que estavam marcadas em suas vidas. Além disso, serviu como uma inspiração de dias melhores para o fazer docente. Como nas palavras da professora Solange "Construir o Geozine, entendê-lo e fazê-lo, reacendeu a minha esperança de dias melhores, onde, com um pequeno bloquinho de papel, é possível desenvolver uma rica e diversificada tipologia de aprendizagem".

\section{CONSIDERAÇÕES FINAIS}

É necessário pensar como ampliar os horizontes docentes em relação às suas práticas. Em outras palavras, é fundamental pensar em construir momentos de formação, um dos principais pontos elencados tanto pelos professores quanto pela avaliação do perfil didático. Por esse motivo, a pesquisa se debruçou no desenvolvimento do Geozine a partir da perspectiva do professor, haja visto que ele é a figura central de todo o processo de ensino. É através dele que se dá as escolhas e os caminhos a se seguir e, junto ao planejamento semanal, quinzenal ou mensal deste ator, que todo o conjunto de ensino se desenvolve. Diante disto, nada melhor que iniciar o processo de construção do Geozine a partir de sua experimentação prévia, criando acepções e "diminuindo" os entraves para desenvolver novas metodologias.

Por conseguinte, iniciar o processo de construção do Geozine, por meio do professor, trouxe novos olhares ao educador. Aproximar uma estratégia, antes da sua aplicação na práxis didática, possibilitou ressurgir a figura do pesquisador, aquele ator que está sempre em processo de novas descobertas e que é movido por questionamentos na busca de um fazer pedagógico significativo para o aluno.

\footnotetext{
${ }^{1}$ Todas as falas e fotográficas dos participantes da pesquisa foram autorizadas pelos mesmos, mediante assinatura de uma declaração de uso (imagem e escrita).
} 
Por isso, o fato do Geozine ser introduzido diretamente ao professor destaca a figura do docente como responsável pelas delimitações de sua ação pedagógica em sala de aula. Além disso, tanto a oficina desenvolvida com o professorado como a análise da práxis da professora Adriana evidenciaram que é um caminho plausível a seguir e que traz consigo uma gama de ressignificações nos "achismos" que todo docente carrega (falta de tempo, falta de iniciativa em criar, falta de pesquisar, etc.), mas mostraram, durante toda a caminhada, um "despertar" e que, sim, é possível. No entanto, requer esforços em não deixar apagar uma das principais marcar de ser professor: a buscar incessante pelo conhecimento.

No terceiro momento, foram expostas as ações desenvolvidas através da oficina Geozine com os professores das três instituições da cidade de Taipu, na busca de compreender como um objetivo didático, experenciado a partir das acepções e vivências da cidade (isto é, utilizando a noção do lugar e a leitura da paisagem taipuense). Essa experenciação trouxe ganhos importantes para todos os autores envolvidos, pois, embora o objetivo tivesse a conotação de propiciar a apreciação de uma nova metodologia, estava muito além disso, tend o em vista que possibilita o desenvolvimento de um espaço de trocas, de professor para professores, em que o conhecimento geográfico de vivências era a principal similaridade.

A experimentação do Geozine apresentou, dentre tantos fatores positivos, a possibilidade do próprio professor ser o autor de suas metodologias em despertar o pesquisador que há em cada educador. Logo, o Geozine compreendeu uma estratégia para o professor que dá diferentes possibilidades na sua aplicação na práxis docente, levando em consideração que tudo depende da intencionalidade e dos direcionamentos do educador no processo da aprendizagem.

Diante de tudo que foi exposto, espera-se que esta pesquisa sirva de inspiração para outros professores de Geografia, contribuindo para que não desistam mediante à realidade imposta pela sociedade. Sobretudo, espera-se que 
os docentes busquem desenvolver ferramentas, metodologias e estratégias que, como o Geozine, seja mais um contributo à ciência geográfica escolar.

\section{REFERÊNCIAS}

BAKHTIN, M. Marxismo e Filosofia da linguagem. São Paulo: Hucitec, 1992.

CAVALCANTI, L. de S. Geografia, escola e construção de conhecimento. Campinas: Papiros, 2010.

CLAVAL, P. A Geografia Cultural. Florianópolis: UFSC, 1995.

CLAVAL, P. Epistemologia da Geografia. Florianópolis: Editora UFSC, 2002a.

DUARTE, E. N. Linguagem e Comunicação Suplementar e Alternativa na Clínica Fonoaudiológica. 2005. 85 f. Dissertação (Mestrado em Comunicação e Artes) - PUC, São Paulo, 2005.

GADAMER, H. G. Verdade de método II: complemento e índice. Tradução: Enio Paulo Giachini. Petrópolis: Vozes, 2002.

MAGALHÃES, H. O que é fanzine. São Paulo: Editora Brasiliense, 1993.

MORIN, E. A religação dos saberes: jornadas temáticas idealizadas e dirigidas por Edgar Morin. Rio de Janeiro: Bertrand Brasil, 2001.

MORIN, E. Introdução ao pensamento complexo. 3. ed. Porto Alegre: Sulina, 2007.

NASCIMENTO, I. S. do. Da Marginalidade à sala de aula: o fanzine como artefato cultural, educativo e pedagógico. In: MUNIZ, Cellina Rodrigues (Org.) Fanzines: autoria, subjetividade e invenção de si. Fortaleza: Edições UFC, 2010.

PONTUSCCHKA, N. N.; PAGANELLI, T.; CACETE, N. H. Para Ensinar e Aprender Geografia. 3. ed. São Paulo: Cortez, 2009.

SANTOS, M. Pensando o espaço do homem. São Paulo: Editora Hucitec, 2000.

SAUSSURE, F. Curso de Linguística Geral. São Paulo: Editora Cultrix, 1989.

SILVA, A. M. G. da. Geozine: Linguagem para o ensino do conteúdo de região na geografia escolar. Dissertação (Mestrado Profissional em Geografia) - Universidade Federal do Rio Grande do Norte, Natal, 2018.

STRAFORINI, R. Ensinar Geografia: o desafio da totalidade mundo nas séries iniciais. São Paulo: Annablume, 2006. 
THOMPSON, J. B. A Mídia e a Modernidade: uma teoria social da mídia. Rio de Janeiro: Petrópolis, 2011.

VITECK, C. M. Punk: anarquia, neotribalismo e consumismo no rock'n' roll. Publicação Espaço Plural, Paraná, n. 16, p.53-58, 2007.

WITTGENSTEIN, L. Investigações Filosóficas. Petrópolis: Vozes, 2005.

\section{1 - João Paulo Teixeira Viana:}

Mestre em Ensino de Geografia - GEOPROF/UFRN, https://orcid.org/0000-0002-3386-7992•jpviana25@yahoo.com

Contribuição: Responsável pela a escrita, dissertação e concepção, é o resultado da dissertação de mestrado.

\section{2 - Eugênia Maria Dantas:}

Professora do Departamento de Geografia - UFRN, Pós-Doutorado no Grupo de Estudos da Complexidade (GRECOM/UFRN),

https://orcid.org/0000-0002-1541-7082•eugeniadantas@yahoo.com.br

Contribuição: Professora orientadora do mestrado do referido autor 1.

\section{Como citar este artigo}

VIANA, J. P. T.; DANTAS, E. M. Construindo uma metalinguagem didática: o geozine na prática docente. Geografia Ensino \& Pesquisa, Santa Maria, v. 25, e39, p. 1-33, 2021. DOI 10.5902/2236499463241. Disponível em: https://doi.org/10.5902/2236499463241. Acesso em: dia mês abreviado. ano. 